\title{
La rebelión de Jacinto Canek en Yucatán: una nueva interpretación
}

\author{
Robert W. Patch
}

La famosa rebelión de Jacinto Canek, en el pueblo de Cisteil en I76I, por falta de información ha sido mal interpretada, ya sea como un motín de borrachos, ya como una sublevación noble en contra de la explotación colonialista. Un estudio del juicio criminal que resultó de la rebelión destaca la naturaleza del fenómeno. Fue una rebelión sumamente seria, con un fuerte contenido anticolonialista, pero las causas parecen ser más de naturaleza cultural que económica. Los mayas siguieron creyendo en una versión cíclica de la historia, la cual les dio a entender que un día en el futuro ellos dominarían a los españoles. Jacinto Canek escogió un nombre con alto significado histórico para los mayas, se proclamó rey y encabezó una rebelión que tuvo por meta el dominio político y religioso de los mayas en Yucatán. Miles de indígenas creyeron que era el rey anunciado por la profecía y que los días de los españoles estaban contados. El movimiento intentó revitalizar la cultura maya después de dos siglos de colonialismo, pero los españoles lograron sofocar la rebelión antes de que se pudiera extender más allá del centro de la Península.

Due to lack of information, the famous rebellion of Jacinto Canek, in the village of Cisteil in I76I, has been misinterpreted, either as a drunkards riot, or as a noble uprising against colonial exploitation. A study of the criminal trial which resulted from the rebellion emphasizes the nature of the phenomenon. It was a highly serious rebellion, with a strong anti-colonialist content. However, the causes seem to be of a cultural rather than an economic nature. The Mayas continued to believe in a cyclic version of history, which led them to think that one day in the future they would overthrow the Spaniards. Jacinto Canek chose a name of historical significance for the Mayas, he proclaimed himself king and led a rebellion, the aim of which was the political and religious domination of the Yucatan Mayas. Thousands of natives believed he was king and that the days of the Spaniards were counted. The movement sought to revitalize Mayan culture after two centuries of colonialism, but the Spaniards managed to suffocate the rebellion before it could spread beyond central Yucatan.

ROBERT W. PATCH: Universidad de California, Riverside.

El autor agradece a Karl Taube, Beatriz Cáceres Menéndez, Gilbert M. Joseph y Sharon Burton por los comentarios vertidos a los borradores previos de este ensayo.

Desacatos, núm. 13, invierno 2003, pp. 46-59.

- Traducción de Gabriela Solís Robleda. 
$\mathrm{L}$ a población indígena de la América española frecuentemente participó en rebeliones contra los españoles y el régimen colonial. Esto es comprensible porque los indios sufrían de la explotación y abuso por los oficiales del gobierno y los colonos españoles. Sin embargo, la historia de los levantamientos, insurrecciones, revueltas, rebeliones y revoluciones demuestra que la explotación, aunque casi siempre una causa necesaria, no siempre es suficiente en sí misma para provocar el estallido de la violencia social. Casi siempre otros factores están implicados y a menudo son cruciales como catalizadores que transforman una previa situación tolerable en otra que abruptamente se torna insufrible.

El presente ensayo se enfoca en destacar el papel relevante que la cultura maya desempeñó en la rebelión de Jacinto Canek en Yucatán en 1761. La novedad del estudio reside en que es el primero basado en la documentación del proceso jurídico que resultó de la sublevación. ${ }^{1}$ Esta fuente ${ }^{2}$ permite un análisis más detallado de la mentalidad de los participantes y aporta información importante sobre el pensamiento y la visión del mundo - es decir, el contenido cultural— de los mayas de Yucatán en el siglo XVIII.

\footnotetext{
${ }^{1}$ Para material de fuentes primarias útiles en el estudio de la rebelión de Jacinto Canek, véase María Teresa Huerta y Patricia Palacios (eds.), Rebeliones indígenas de la época colonial, México, 1976, pp. 174-189. Una valiosa fuente secundaria es Justo Sierra O'Reilly, Los indios de Yucatán, 2 vols., Mérida, 1954, t. II, pp. 19-35. Para estudios modernos sobre la rebelión, véase Miguel A. Bartolomé, La insurrección de Canek. Un movimiento mesiánico en el Yucatán colonial, México, 1978; Victoria Reifler Bricker, The Indian Christ, the Indian King: The Historical Substrate of Maya Myth and Ritual, Austin, 1981, pp. 70-76; y Nancy M. Farriss, Maya Society Under Colonial Rule: The Collective Enterprise of Survival, Princeton, 1984, pp. 68-72. Ni Bartolomé ni Bricker consultaron los documentos del juicio en el Archivo General de Indias, por lo que sus interpretaciones difieren de manera significativa de la mía.

${ }^{2}$ El proceso se encuentra en el Archivo General de Indias (en adelante citado como AGI), México 3050, año de 1761, Testimonio de Autos fhos. Sobre la Sublevación que hizieron varios Pueblos de esta Provincia en el de Cisteil en el que aclamaron por Rey a Joseph Lacinto Uc de los Santos Canek Yndio Natural del Barrio de Campechuelo en el Puerto de San Francisco de Campeche. Este documento se cita en adelante como Testimonio de Autos fhos. (1761). Existe una copia, que se encuentra también en el legajo México 3050: Autos Criminales Seguidos de Ofisio de la Real Justisia sobre la sublevación que los Yndios del Pueblos de Cisteil y los demas que convocaron hicieron contra ambas Magistades el dia 19 de Noviembre de 1761 (1761-1762), que será citado como Autos Criminales (1761-1762).
}

\section{LA COMUNIDAD MAYAY EL PUEBLO DE CISTEIL}

La sublevación de 1761 ocurrió en el pueblo de Cisteil. No hay evidencia de la existencia del pueblo hasta el año de 1755, cuando es mencionado en un informe sobre el sistema de repartimientos en Yucatán. ${ }^{3}$ Se puede concluir que Cisteil era, desde el punto de vista oficial, un pueblo de reciente fundación, pues los registros gubernamentales y eclesiásticos eran muy detallados y ni la Iglesia ni el Estado estaban dispuestos a omitir en los registros la presencia de un pueblo organizado.

La investigación del gobierno sobre la rebelión brinda importante información acerca de la naturaleza de Cisteil. Fue identificado como una parcialidad del pueblo cercano de Tixcacaltuyú. ${ }^{4}$ El término parcialidad comenzó a utilizarse en el siglo XVI para referirse a una subunidad autónoma y separada de un asentamiento. Muchas subunidades, que los españoles llamaron parcialidades, ya existían en tiempos prehispánicos en la forma de barrios llamados en maya cuchteelob (sing. cuchteel). Otros aparecieron después de la conquista como resultado de la política colonial de reducción, esto es, la reubicación forzosa de indígenas de un lugar a otro que previamente existía.

La fundación de Cisteil, como la de muchos otros pueblos, fue producto de algo más que sólo el resultado de la dispersión de unas familias debido a la falta de tierras para hacer sus milpas. ${ }^{5}$ La Iglesia y la Corona coloniales consideraban como un serio problema el abandono de los pueblos, porque las autoridades suponían que con la huída los indígenas estaban abandonando la civilización y

\footnotetext{
${ }^{3}$ Véase AGI, Sevilla, México 3048, Testimonio hecho en virtud de un despacho del Gobernador y Capitán Gral. de aquella Provincia, sobre el repartimiento de patíes y cera en los pueblos de yndios de ella (1755), fol. 75 .

${ }^{4}$ Testimonio de Autos fhos. (1761), fol. 5 .

${ }^{5}$ La tendencia natural hacia la dispersión como resultado de factores ecológicos está bien explicada en Nancy Farriss, "Nucleation Versus Dispersal: The Dynamics of Population Movement in Colonial Yucatan", HAHR, vol. 58, núm. 2, 1978, pp. 187-216; y en Farriss, Maya Society, pp. 125-131. Sigo esta interpretación hasta cierto grado en mi artículo "Decolonization, the Agrarian Problem, and the Origins of the Caste War of Yucatan, 1812-1847”, en Jeffery T. Brannon y Gilbert M. Joseph (eds.), Land, Labor, and Capital in Modern Yucatan: Essays in Regional History and Political Economy, University, Alabama, 1991, pp. 51-82.
} 
el cristianismo y tratando de evitar el pago de sus tributos. $\mathrm{Y}$ desde luego que algunas veces los mayas hicieron precisamente eso. Sin embargo, a menudo la migración de los viejos asentamientos a otros no condujo al colapso de la civilización sino a la colonización de nuevas tierras y a la recreación concomitante de la política y sociedad mayas en nuevas áreas.

Un proceso similar parece haber tenido lugar en el caso de Cisteil. Como ya hemos dicho, este pueblo no aparece en los documentos coloniales antes de 1755 . Lo reciente del asentamiento se refleja en el origen de los prisioneros interrogados después de la sublevación: de todos los residentes de Cisteil sólo una persona se identificó como natural del pueblo; todos los demás declararon ser residentes de Cisteil pero naturales de otros lugares. Sin embargo, cuando este pueblo aparece por vez primera en los documentos ya tenía un cabildo con alcaldes, regidores, alguaciles, topiles y escribano. ${ }^{6}$ Probablemente no tenía cacique porque el principal oficial maya era identificado como teniente. Pero en la misma situación estaban muchos otros asentamientos mayas, lo que probablemen- mantenían los lazos con la comunidad de origen y los inmigrantes se ceñían a verdaderos y probados patrones de comportamiento cultural.

Por tanto la migración maya, continuamente denunciada por eclesiásticos y burócratas, muy rara vez se traducía en el abandono de la sociedad para vivir fuera de los límites de la civilización. Muchos mayas dejaban sus pueblos de origen sólo para crear nuevas comunidades en otra parte. Algunas veces las migraciones se llevaban a cabo por individuos que se movían en grupos mayores que la unidad familiar. Cisteil fue el resultado del movimiento de una parcialidad completa a un nuevo sitio. Así, la "dispersión" maya constituía a menudo simplemente un paso hacia la fundación de nuevos pueblos por una sociedad que estaba en movimiento constante.

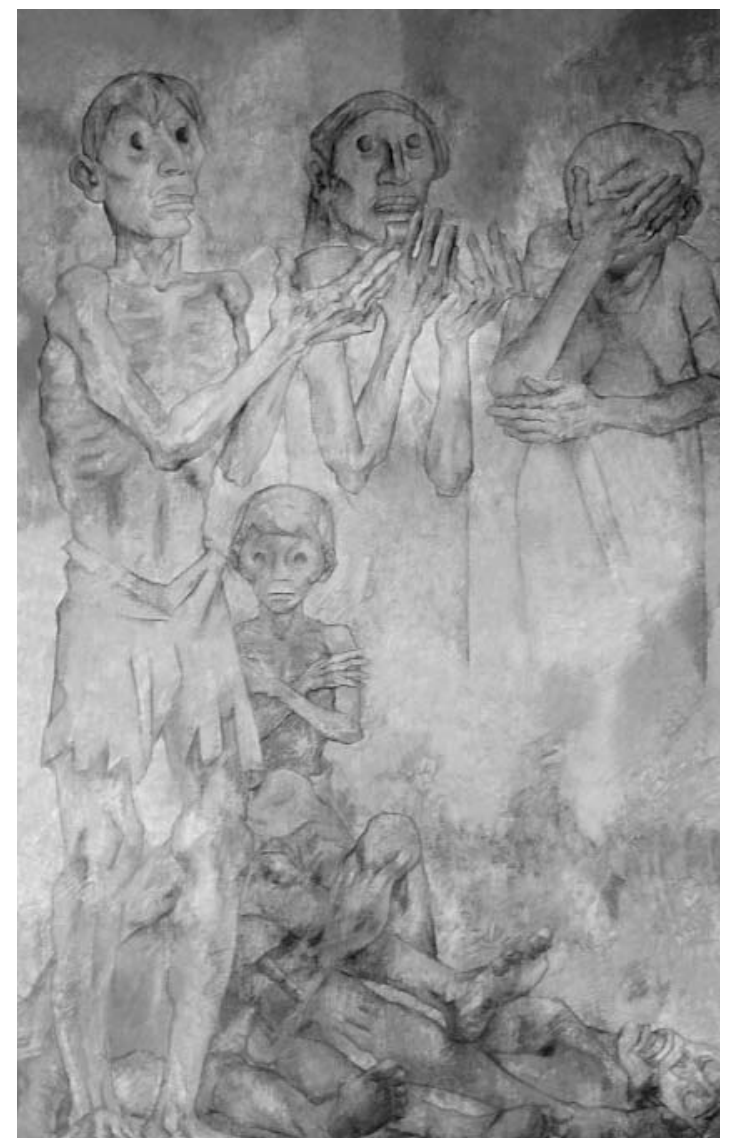

Fernando Castro Pacheco, Sequía, peste y hambre.
${ }^{6}$ La palabra topil es de origen náhuatl. En el México central este término, como oficial que ocupaba un cargo público, se añadió a otras palabras para especificar las funciones que debía desempeñar el que ejercía el cargo. Véase S. L. Cline, Colonial Culhuacan, 1580-160o. A Social History of an Aztec Town, Albuquerque, 1986, p. 41.

7 Para ejemplos de esto, véase AGI, Escribanía de Cámara 327, Causa criminal fulminada en virtud de Comision de S. M. por el Sr. don Juan Joseph de Vertiz... contra el Tesorero de la Santa Cruzada... (1716), fols. 135, 139, 177, 179, 183, 201, 218, 234, 241, 251, 253. 


\section{LA SUBLEVACIÓN DE I76।}

Los eventos de 1761 deben ser analizados en este contexto de movilidad geográfica de la población, de continuidad de normas culturales mayas y de creación de nuevas comunidades. Sin embargo, el hecho de que los eventos de aquel año hayan constituido una rebelión es cuestionable. Aquellos que se unieron al movimiento jefaturado por Jacinto Canek lo hicieron obedeciendo las órdenes de quien —estaban convencidos — era el legítimo rey. Algunos incluso dijeron haber entendido que Canek era Carlos III de España. Este hecho revela la enorme magnitud de la incomprensión existente entre españoles e indios. A lo largo del juicio el gobernador y su teniente preguntaron reiteradamente a los prisioneros cómo era posible que "con tan poco temor de Dios" ellos pudieran haber creído que un indio fuera el rey cuando el único monarca era Carlos III de España. Un prisionero respondió astutamente "que no save que ay Rey de España, y que no ay mas Rey que Dios". La mayoría simplemente afirmó que ellos de hecho creyeron que Canek era rey. Lo que parecía ridículo a los españoles no lo era para los mayas. Por lo tanto, la sublevación de 1761 fue más una afirmación que un rechazo de la autoridad legal. Lo que estaba en disputa era quién representaba la autoridad legal.

La sublevación no se dio como resultado de ningún factor específico. Ciertamente el propio Canek abolió el tributo y el sistema de repartimiento, de lo que se infiere que ambos fueron causas significativas. Pero de hecho, estos mecanismos coloniales de explotación habían existido por siglos y probablemente no eran peores en 1761 de lo que habían sido antes. Que la explotación colonial fue una causa necesaria, pero no suficiente, para la sublevación, es más que una probabilidad. Más aún, sólo dos de los prisioneros mencionaron en el juicio la explotación y los abusos como factores que influyeron en su decisión de unirse al movimiento 9 (aunque uno de éstos declaró que la rebelión se suscitó porque los indios "estaban aburridos de servir a los españoles").10 La guerra de castas

\footnotetext{
${ }^{8}$ Autos Criminales (1761-1762), fol. 314

9 Testimonio de Autos fhos. (1761), fol. 130.

${ }^{10}$ Testimonio de Autos fhos. (1761), fol. 130. Declaración de Francisco Puc
}

que se inició en 1847 en parte sería causada por la rápida expansión de las haciendas a expensas de las propiedades indígenas, ${ }^{11}$ pero la rebelión de 1761 no tenía nada que ver con las incursiones españolas en el territorio indígena. Por tanto, las causas deben ser de naturaleza diferente.

En los juicios criminales de los prisioneros aprehendidos en la batalla de Cisteil hay pistas importantes en relación con estas causas. Desde luego que esta fuente debe utilizarse con precaución porque en la historia muchos individuos que han tenido la oportunidad de hablar han dicho solamente lo que sus jueces, inquisidores, captores o torturadores han querido que digan..$^{12} \mathrm{Sin}$ embargo, en este caso los jueces españoles hicieron un esfuerzo para determinar quién era culpable y quién no. Muchos prisioneros rechazaron la evidencia que se presentaba en su contra y eventualmente fueron exonerados. Consecuentemente, la documentación del juicio sí contiene valiosa información y por tanto puede ser utilizada como cualquier otro documento histórico. Como una vez dijo Marc Bloch, las fuentes son como testigos: hay que interrogarlas.

La mejor manera de explicar la sublevación es empezar con el personaje Jacinto Uc de los Santos. Natural del barrio de Laboríos en el puerto de Campeche, Uc tenía 30 años en 1761. Años después se dijo que él había recibido algún tipo de educación de los franciscanos, aunque esto no se mencionó en su juicio. ${ }^{13}$ En el año de la rebelión era viudo; de hecho, sólo dos de los prisioneros varones adultos capturados durante la sublevación - Canek y un mendigo/brujo — no estaban casados.

\footnotetext{
${ }^{11}$ Véase Patch, "Decolonization, the Agrarian Problem, and the Origins of the Caste War", 1991.

12 Para comentarios expertos en relación con la necesidad de precaución al utilizar la información de los juicios, véase Eric Van Young, "The Cuautla Lazarus: Double Subjectives in Reading Texts on Popular Collective Action", Colonial Latin American Review, vol. 2, núms. 1-2, 1993, pp. 3-26.

${ }^{13}$ Esto fue mencionado por un eclesiástico que escribió más de 20 años después de la rebelión. Véase Archivo de la Mitra Emeritense (Mérida, Yucatán), Visitas Pastorales, Mocochá, enero 20 de 1785. La única referencia a alguna relación entre los franciscanos y Jacinto Uc en los registros del juicio es la declaración de un brujo sobre que un sacerdote en Valladolid le había preguntado "si conosía a un Yndio que tenía en el Comvento, de Campeche, llamado Canek”. Autos Criminales, fol. 331.
} 
Jacinto Uc vivió una vida singular, muy diferente a la del común de los mayas. Sus actos hablan de un hombre que se creyó y se condujo como un chamán. Peregrinaba solo a través de la provincia como mendigo y adivinador y posiblemente concurría a los rituales paganos que se llevaban a cabo en los montes al sur, en el área fuera del control español. También pudo haber deambulado cerca de Belice porque después declaró haber tenido contacto con los ingleses y que había sido traído a Yucatán en un barco inglés. Curó a los enfermos y prometió que con un aceite sagrado, hecho de calabaza y miel, devolvería la vida a los muertos. En lugar de carne, comió flores de jazmín. Intentó convencer a los demás que podía volar. Durante su juicio, al ser interrogado por su oficio, dijo ser mayordomo de Jesús Nazareno. ${ }^{14}$

En octubre de 1761 Jacinto Uc apareció en Chikindzonot, un pueblo del Yucatán central. Dijo ser el rey cuya venida había sido profetizada en la Biblia. Pero por el esfuerzo de propagar su mensaje no recibió más que azotes dados por el cura del pueblo.

Entonces Uc se fue al poblado cercano de Tiholop, aquí los azotes dados en Chikindzonot le favorecieron, porque usó sus heridas para probar que él había sido azotado en la columna y que verdaderamente era Cristo el Rey. Habló con los principales del cabildo indígena, les informó que pronto sería coronado rey en el pueblo de Cisteil y les prometió que después de su coronación enviaría órdenes para que los indígenas de Tiholop se le unieran. ${ }^{15}$ Jacinto Uc partió para Cisteil e informó a los principales indígenas que él era "Montezuma" (Moteuhcçoma), el rey cuya venida había sido profetizada. El principal oficial del pueblo, el teniente Joseph Chan, primero dudó de la proclama de Uc al percatarse de que, aunque se esperaba la llegada de Moteuhcçoma a la provincia, él debía venir vestido como rey. Uc respondió que había venido disfrazado como indio para que los españoles no lo reconocieran. Entonces, para probar su legitimidad,

14 Testimonio de Autos fhos. (1761), fols. 187-188; Autos Criminales (17611762), fol. 270. Se dijo que utilizó "maguey quemado" (probablemente sábila) para curar heridas.

15 Testimonio de Autos fhos. (1761), fols. 164-168. ordenó que le trajeran todos los recibos por pago de tributos, los quemó - un acto de gran significado simbólico-y proclamó que todos los bienes de repartimiento le pertenecían por derecho. También mandó a sus seguidores matar todos sus cochinos porque — dijo- los cerdos tenían almas españolas y el sacrificio de estos animales permitiría que los mayas mataran a los españoles. ${ }^{16}$ Se reunió con los líderes religiosos del pueblo para realizar rituales nocturnos. Su comportamiento como chamán convenció a los indígenas del pueblo que él era el rey. Y cuando los líderes religiosos de Cisteil declararon que Uc era el monarca legítimo, fue coronado Jacinto Uc de los Santos, Can Ek, Rey Montezuma. A partir de este momento, todos los indios que se encontraban con Uc se dirigían a él como rey y le besaban la mano al tiempo que inclinaban la cabeza. ${ }^{17}$

Otros pueblos comenzaron a mandar a sus principales para examinar al hombre que dijo ser rey y Uc los convenció de que él era en efecto el esperado rey que la profecía - tanto maya como cristiana- había anunciado que vendría del "Oriente" para gobernar al mundo y empezar un nuevo ciclo en la historia. Tomás Balam, escribano de Tixméuac, por ejemplo, declaró en el juicio que "creyó, que era Rey, porque se decía, havía de venir, y vino, del Oriente". ${ }^{18}$ La noticia del arribo del rey se extendió y pronto miles de personas de los pueblos adyacentes peregrinaban a Cisteil para verlo por ellos mismos. Simón Maas, maestro de coro de Tixméuac, después declaró que dejó su pueblo "a reconocer a un Canek, a quien según tuvieron noticia, havía electo Rey para rendirle obediencia, y venerarlo, en caso de ser tal Rey". 19 No todos los indios estaban convencidos. Luis Cauich, maestro de coro de Cisteil, declaró que Uc era un fraude y eventualmente huyó a Tixcacaltuyú a informar al cura de ese lugar lo que estaba pasando. Sin embargo, parece que la mayoría de los mayas en Cisteil aceptaron a Uc como rey y creyeron que el tiempo anunciado en la profecía había llegado.

\footnotetext{
${ }^{16}$ Autos Criminales (1761-1762), fols. 295-304

17 Autos criminales (1761-1762), fols. 245-247.

18 Testimonio de Autos fhos. (1761), fol. 151.

19 Testimonio de Autos fhos. (1761), fol. $153 \mathrm{ff}$.
} 
Por tanto, la verdadera razón de la sublevación fue cultural: a pesar de los dos siglos de colonialismo y cristiandad, los mayas continuaban creyendo que el tiempo no se movía a lo largo de un continuum sino en ciclos y que el régimen colonial era sólo una fase en esta historia cíclica. De hecho, los españoles eran vistos simplemente como otro grupo conquistador que eventualmente sería depuesto e integrado a la sociedad indígena. Desde luego que al comenzar la sublevación los miembros de la sociedad española-criolla creyeron que los indios iban a exterminarlos. Se supone que muchos mayas pensaban, o esperaban, hacerlo. Pero en Cisteil, Canek, de acuerdo con testigos, declaró que las mujeres españolas serían obligadas a casarse con los indios y que él mismo tendría la primera oportunidad de elegir a su esposa. ${ }^{20}$ La meta por lo tanto no era la exterminación sino la asimilación del conquistador, como en el caso de los itzaes muchos siglos antes. ${ }^{21}$ Parece que algunos españoles, desde el principio, entendieron esto. Observadores conocedores señalaron que lo que estaba pasando era percibido por los mayas como el futuro predicho en los libros del Chilam Balam. En cierto sentido esto era más atemorizante aún que la rebelión misma (y explica por qué un maya, cuando menos, fue arrestado por simplemente mencionar el Chilam Balam). ${ }^{22}$

En realidad, los mayas que participaron en el movimiento no estaban resistiéndose a la autoridad; la estaban reclamando para sí mismos. Por esta razón no hicieron ningún intento para negociar con el gobierno español para reparar los notorios agravios del colonialismo. Esto contrasta tajantemente con la guerra de castas del siglo XIX, porque durante ese conflicto un jefe maya sí intentó negociar con el gobierno y presentó una lista de agravios que puede ser usada para entender las causas del levantamiento de 1847.23 Para los líderes y participantes en la

20 Testimonio de Autos fhos. (1761), fol. 131.

${ }^{21}$ Véase Inga Clendinnen, Ambivalent Conquest. Maya and Spaniard in Yucatan, 1517-1570, Cambridge, 1987, pp. 134-169.

22 Testimonio de Autos fhos. (1761), fol. 143ff. Para una discusión acerca de la importancia de los libros del Chilam Balam, véase Clendinnen, Ambivalent Conquest, pp. 134-169.

23 Véase Patch, "Decolonization, the Agrarian Problem, and the Origins of the Caste War of Yucatan”, 1991. sublevación de 1761, los objetivos del movimiento no eran negociables.

El movimiento mesiánico de Cisteil se transformó en una insurrección por la necesidad del líder de probar su autoridad. Un comerciante ambulante español llamado Diego Pacheco se convirtió en la primera víctima. Pacheco se hospedaba en el mesón de Cisteil, un edificio que todos los pueblos estaban obligados a mantener para albergar a los viajeros españoles. Uc y sus recién designados oficiales — de hecho miembros del cabildo de Cisteilfueron al mesón y le preguntaron a Pacheco el motivo de su permanencia en el pueblo, a lo que respondió que como español tenía el derecho de permanecer en el edificio. También declaró que Canek era un "borracho". El rey ordenó a sus hombres que mataran a Pacheco. Este fue un momento crucial en la historia del movimiento porque cualquier titubeo hubiera conducido al colapso de la autoridad de Uc; la obediencia a las órdenes del rey sería percibida por todos como una señal de que una nueva era realmente se perfilaba. Pacheco fue ajusticiado. La suerte estuvo echada.

Fue en este momento que el maestro de coro huyó del pueblo para informar a las autoridades en Tixcacaltuyú sobre los sucesos en Cisteil. Horas después un destacamento de 20 hombres bajo el mando de Tiburcio Cosgaya, el capitán a guerra de Sotuta, entró al pueblo para restablecer el orden. Los mayas atacaron a los españoles con palos, machetes, estacas y unas pocas armas de fuego. Sólo cuatro hombres del destacamento escaparon con vida y regresaron a Tixcacaltuyú. El resto falleció, incluyendo al capitán Cosgaya. Los cuerpos fueron desnudados y arrojados a un pozo de piedra caliza.

Entonces tanto los españoles como los mayas movilizaron sus fuerzas. En pocos días un destacamento de cientos de milicianos españoles se reunió en Peto (situado como a $20 \mathrm{~km}$ al sur de Cisteil) bajo el mando de Cristóbal Calderón, capitán a guerra de Tihosuco (quien al principio de la sublevación estaba ausente de su cargo realizando la venta de bulas de Cruzada, el negocio de su familia). ${ }^{24}$ En Cisteil Canek animó a sus seguidores

\footnotetext{
${ }^{24}$ En Yucatán la Santa Cruzada vendía bulas de indulgencia a los mayas a través del sistema de repartimiento. Para un análisis de la Cruzada y
} 
diciéndoles que pronto recibirían ayuda de los ingleses y de los indios mosquito. Al mismo tiempo, los líderes de Cisteil escribieron cartas a muchos caciques de Yucatán informándoles de la llegada del rey y requiriéndoles el envío de ayuda. Se sabe que estas cartas fueron enviadas a destinos tan lejanos como Maxcanú y aun Uxmal (ubicados a 110 y $90 \mathrm{~km}$ al oeste, respectivamente). ${ }^{25}$

El movimiento de Cisteil tuvo un importante significado cultural para los mayas. Canek fue el nombre del último gobernante de los mayas itzaes independientes. ${ }^{26}$ La selección del nombre y el haber escogido Uxmal como uno de los destinos de las cartas enviadas en solicitud de ayuda sugieren que los mayas sabían más de su historia de lo que sospechaban los

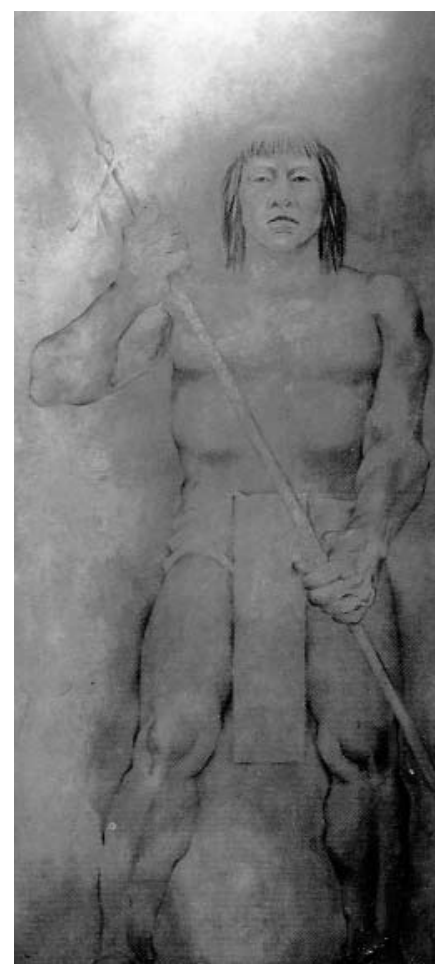

Fernando Castro Pacheco, Nachi Cocom. a su pueblo y que emigró después de prometer que regresaría en el futuro. En algunas versiones de esta leyenda, Moctezuma era visto además como el protector de la religión indígena contra la cristianidad..$^{28}$ Se puede concluir que en esta región el emperador azteca, en forma de leyenda, era un héroe cultural. Éste era quizás también el caso en Yucatán, aunque todavía no se ha encontrado ninguna evidencia. Es posible que Moctezuma fuera el único gobernante azteca conocido por los mayas de Yucatán y simplemente se entendía que representaba la autoridad legítima. ${ }^{29}$

Canek, a la cabeza de su grupo y portando una vara de justicia, comenzó a designar cargos para formar su gobierno (aunque como prisionero negó haber realizado esas designaciones). Supuestamente nombró a Joseph Chan, el teniente de Cisteil, como gobernador y capitán general, de su poder de Cisteil a Maní, la vieja capital de la dinastía Xiu antes de la conquista española. ${ }^{27}$ Así, el movimiento y sus líderes tenían un sentido histórico. También conocían algo de la historia de los aztecas porque Canek fue proclamado como el rey "Moctezuma”. Sólo podemos especular acerca del significado que los mayas atribuían al nombre de dos de los emperadores aztecas. La leyenda de Moctezuma fue conocida por los indios de lo que ahora es el suroeste estadounidense y el noroeste mexicano, éstos pensaban que el emperador azteca había sido un gran líder que trajo prosperidad

del repartimiento en el Yucatán colonial, véase Patch, Maya and Spaniard, caps. 4 y 6.

25 Testimonio de Autos fhos. (1761), fols. 62, 129.

${ }^{26} \mathrm{El}$ nombre Canek fue conocido en la selva del sur a lo largo del periodo colonial. Tan tardíamente como 1786, el nombre de un líder indígena en el área semicolonizada del Petén era Pedro Canek Bisnieto. Véase AGI, Guatemala 572, Carta del Obispo de Yucatán al Rey, 27 de junio de 1786, y Carta del Gobernador de Yucatán al Rey, 29 de julio de 1786.

${ }^{27}$ Testimonio de Autos fhos. (1761), fol. 167. pero enseguida procedió a nombrar a una segunda persona con el mismo cargo. Quizás Canek no había comprendido cabalmente las instituciones políticas españolas, o bien estaba regresando a una tradición maya mucho más antigua consistente en tener dos capitanes sirviendo al mismo tiempo. ${ }^{30}$ Proclamó que a partir de ese momento los indios no deberían acudir a Mérida

\footnotetext{
${ }^{28}$ Richard J. Parmentier, "The Mythological Triangle: Poseyemu, Montezuma, and Jesus in the Pueblos", en William C. Sturtevant (ed. general), Handbook of North American Indians, vol. 9, Washington, 1979, pp. 617-620.

${ }^{29}$ Para una posible relación de la leyenda de Moctezuma con los mayas, véase Arthur G. Miller, On the Edge of the Sea: Mural Painting at Tancah-Tulum, Quintana Roo, Mexico, Washington, Dumbarton Oaks, 1982, p. 92. Quisiera agradecer a Karl Taube por llamar mi atención sobre esta cita.

30 "Dos capitanes tenían siempre: uno perpetuo (cuyo cargo) se heredaba, y otro elegido por tres años con muchas ceremonias": Diego de Landa, Relación de las cosas de Yucatán, Porrúa, México, 1973, p. 52. Quisiera agradecer otra vez a Karl Taube por llamar mi atención sobre esta cita.
} 
para confirmar sus elecciones pues el propio Canek lo haría en Cisteil. En síntesis, Canek asumió las funciones oficiales del gobierno español. También se autoproclamó como líder religioso, consagró a nuevos sacerdotes (quienes se vestían con los atuendos de sacerdotes católicos), administró los sacramentos, rezó el rosario y condujo la novena en honor de Nuestra Señora, incluso se puso en la cabeza la corona de la Virgen, tomada de la estatua de la iglesia de Cisteil. Además, se dijo que Canek había declarado que Nuestra Señora era su esposa, "por ser Rey de la tierra”. ${ }^{31}$ Proclamó ser enviado de Dios en una misión y - lo que escandalizó a la clerecía católica - toda la jerarquía religiosa maya de Cisteil y de los pueblos cercanos, con la excepción del maestro de coro Luis Cauich, avalaron el reclamo del rey de ser el

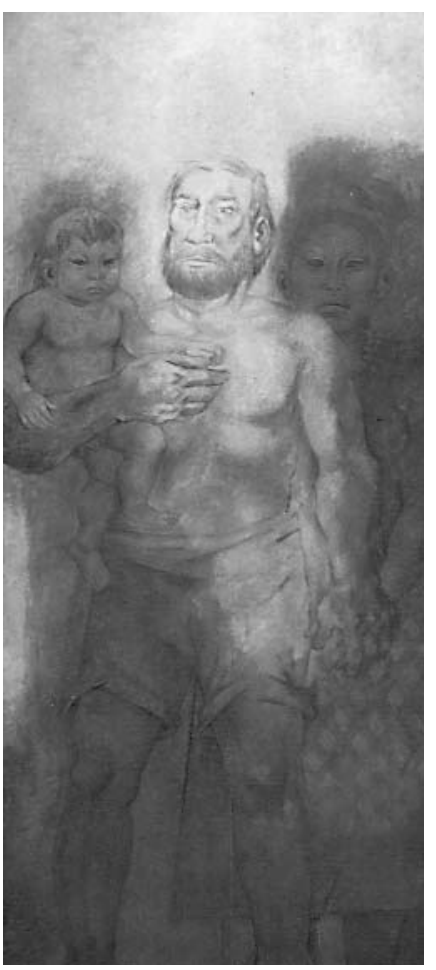

Fernando Castro Pacheco, Gonzalo Guerrero. indios se volvían irrespetuosos y en otros, los oficiales españoles encontraron que la población indígena estaba alborotada a causa de estos eventos. Muchos mayas dejaban sus pueblos, a veces de manera masiva, para visitar al esperado rey. Los oficiales coloniales empezaron a confiscar todas las armas de fuego y a arrestar a todos los caciques. Incluso los líderes mayas de los barrios de Mérida fueron detenidos. Los españoles de Yucatán decidieron no correr riesgos.

No todas las actividades de los mayas en ese momento permiten un análisis fácil. Sin lugar a dudas sorprendió a los españoles el consentimiento de los indios a la orden de matar a sus cochinos, aún en pueblos lejanos a Cisteil, pues esto se reportó en Tekax, Nenelá, Tixméuac, Tiholop y Estancia Huntulchac, mientras que los de Pencuyut aparentemente enviaron un mensajero a Cisteil para averiguar si era el tiempo correcto para matar a sus cerdos. ${ }^{33}$ También resulta sorprendente para el observador moderno, considerando la importancia de la porcicultura en la economía maya. En el propio Cisteil, Canek supuestamente llevaba a cabo actos simbólicos cuyo contenido nos es desconocido. Después de cortar la mano o el brazo derecho del capitán Cosgaya "se lo amarraron al Rey en el culo, para que le sirviese de rabo" 34 También ordenó que se sacaran los ojos a los cadáveres de los españoles y que se los trajeran, los colocó en un cáliz y los exhibió ${ }^{35}$ (se supone que esto se hizo — si de verdad sucedió- para probar a los indios recién llegados que realmente habían matado españoles). El rey organizó la producción de una sustancia derivada de la corteza de la lima como un sustituto — sin duda ineficaz- de la pólvora. Y para

\footnotetext{
33 Testimonio de Autos fhos. (1761), fols. 61, 66, 90, 114, 119, 138.

${ }^{34}$ Testimonio de Autos fhos. (1761), fol. 130.
35 Testimonio de Autos fhos. (1761), fol. 131.

34 Testimonio de Autos fhos. (1761), fol. 130
35 Testimonio de Autos fhos. (1761), fol. 131.
}

31 Testimonio de Autos fhos. (1761), fol. 182; Autos Criminales (17611762), fol. 227.

después de la rebelión declaró como ocupaciones: fiscal de doctrina, alguacil de doctrina, cantor de iglesia y maestro de coro o maestro de capilla. Los primeros dos cargos son la traducción al español en dos maneras distintas de una sola función, probablemente la de catequista. Se puede asumir que el cantor era un miembro del coro y el maestro, tanto de coro como de capilla, era un jefe del coro. Todos estos cargos eran, desde luego, posiciones ocupadas por seglares y, por tanto, abier tas para los indios. La existencia de estos cargos permitió a los maya participar de alguna manera en el ritual religioso católico, que de ot por los españoles. 
alentar a sus soldados para que pelearan con valentía en la próxima batalla contra los españoles, Canek predicó a sus seguidores que las balas europeas no los podrían matar ${ }^{36}$ (esto recuerda las revueltas tepehuana y tarahumara del siglo XVII en el norte de México ${ }^{37}$ y la rebelión de los boxers en China al fin del siglo XIX). También les dijo a sus seguidores que morirían sólo si movían sus labios (es decir, gritar con terror); el capitán Calderón reportó que durante el combate cientos de indios murieron sin proferir un sonido. ${ }^{38}$ Canek elaboró aceite sagrado a partir de la calabaza cocida y endulzada y ordenó que se le administrara a los muertos para hacerlos volver a la vida. ${ }^{39}$

No todos los españoles se dieron prisa en presentar batalla contra los mayas. Por lo menos un capitán sospechosamente dijo estar enfermo, mientras que otro no se unió a las fuerzas del capitán Calderón a causa de una supuesta controversia acerca de la estrategia a seguir. Sin embargo, Calderón estaba convencido de que un ataque frontal acompañado con descargas de artillería sería suficiente para quebrar la voluntad de los rebeldes "perros indios", como él llamaba a los indígenas en Cisteil. Su opinión se fundaba en los informes rendidos por un espía maya enviado al pueblo a reconocer las fortificaciones construidas ante la iglesia de Cisteil. Habiendo identificado el punto débil de la defensa maya por medio del espía, el ataque empezó a las tres de la tarde del 26 de noviembre de $1761 .{ }^{40}$ La artillería, con dos pequeños cañones, se concentró en el punto débil. Las fuerzas de Calderón, que contaban con más de 500 hombres, rompieron las líneas defensivas mayas y la carnicería empezó. Aparentemente todos los prisioneros tomados en combate fueron justiciados de manera sumaria. ${ }^{41}$ Más de 500 indígenas

36 Testimonio de Autos fhos. (1761), fols. 71, 131.

${ }^{37}$ Edward H. Spicer, Cycles of Conquest. The Impact of Spain, Mexico, and the United States on the Indians of the Southwest, 1533-1960, Tucson, 1962, pp. 28-29.

38 Testimonio de Autos fhos. (1761), fol. 117.

${ }^{39}$ Testimonio de Autos fhos. (1761), fols. 175-176, 182. Jacinto Uc admitió la mayoría de estos cargos durante el juicio.

${ }^{40}$ El informe del capitán Calderón después de la batalla se encuentra en Testimonio de Autos fhos. (1761), fols. 113-114. A este informe le siguió otro en ibid, fols. 117-118.

${ }^{41}$ Esto lo sugiere el hecho de que ninguno de los prisioneros enjuiciados fuera capturado en Cisteil. murieron en Cisteil y sin lugar a dudas otros fueron ejecutados en diversos lugares; el escribano de Tiholop, por ejemplo, fue ahorcado en ese pueblo sin el beneficio de un juicio. ${ }^{42}$ Las bajas del lado español fueron de solamente 40 muertos, aunque también hubo numerosos heridos. En los próximos días cientos de mayas fueron capturados, muchos rindiéndose después de que Calderón había ordenado un alto a la matanza y ofrecido buen trato a aquellos que se entregaran. El capitán también convenció a las muchas mujeres escondidas en la sabana cerca de Cisteil, quienes habían abandonado su pueblo antes de la batalla, a regresar para enterrar a sus familiares.

\section{EL JUICIO}

El juicio de los prisioneros empezó el 30 de noviembre de 1761, sólo cuatro días después de la batalla de Cisteil. Algunos de los líderes, incluyendo a Canek, estaban entre los prisioneros, todos los cuales fueron interrogados mediante intérpretes. Muchos se defendieron aduciendo que ellos solamente habían seguido las órdenes de los líderes legítimos de sus pueblos o de la persona que ellos creían era su legítimo rey. Otros declararon que habían perdido el juicio o que el demonio los había engañado. El 8 y 9 de diciembre, Jacinto Uc de los Santos, Canek, apareció en la sala de justicia. Como ya vimos, cuando se le preguntó su oficio, respondió que era mayordomo de Jesús Nazareno. Al principio admitió la mayoría de los cargos que se le hicieron, pero al segundo día del interrogatorio se rehusó a testificar.

El 11 de diciembre empezaron a librarse las sentencias. El ex-rey de los mayas debía ser despedazado con tenazas y "luego que muera naturalmente" 43 su cuerpo sería quemado y sus cenizas esparcidas al viento. Ocho más serían ahorcados, se les cortarían las cabezas y manos para ser expuestas en toda la provincia de manera que los indios pudieran ver las consecuencias de la rebelión. Se ejecutaron las sentencias el 14 de diciembre de 1761 .

42 Autos Criminales (1761-1762), fols. 292-294.

43 Testimonio de Autos fhos. (1761), fol. 194. 
Al día siguiente otros 115 mayas fueron sentenciados a sufrir 200 azotes, la mutilación de una oreja y seis años de trabajos forzosos para la Corona. El 25 de enero de 1762 otros 134 fueron sentenciados, y aunque el teniente de gobernador - quien había perdido un pariente en la rebelión y estaba empeñado en la venganza- intentó imponer la pena capital a seis de ellos, el gobernador decidió que ya eran suficientes las muertes y que era necesario asegurar a los indios que todo volvería a la normalidad. Por tanto, sentenció a esos seis indios a sufrir 200 azotes y ocho años de exilio y trabajo forzoso en los astilleros de su majestad en La Habana. A otros seis se les dieron 100 azotes y seis años de exilio en Bacalar. De los 122 restantes, a 91 se les dieron 200 azotes y seis años de trabajo forzoso para la Corona y a 31 se les dio sentencia de 50 azotes y dos años de trabajo forzoso. Por otro lado, Luis Cauich, el maestro de coro que huyó de Cisteil para advertir a los españoles, y Melchor Aké, el espía que había reconocido las líneas defensivas de los indios, fueron recompensados otorgándoles el estatus de hidalgo (noble). ${ }^{4}$

Los documentos del juicio nos permiten percibir los eventos de 1761 como un movimiento social. Los españoles registraron el pueblo de origen de todas las 258 personas sentenciadas por su participación en la rebelión. Como sólo una persona era natural de Cisteil, ciertamente que el grupo incluye no solamente individuos de otros pueblos que se unieron al movimiento en 1761 sino también a un gran número de residentes de Cisteil que habían migrado previamente al nuevo asentamiento desde otros lugares y por tanto se identificaron como naturales de su pueblo de origen. En síntesis, el grupo es representativo por su participación, tanto en el movimiento de $1761 \mathrm{co-}$ mo en el proceso de migración y colonización de nuevas tierras. El pueblo que tenía el mayor número de individuos en el grupo de sentenciados era Tixcacaltuyú con 48 , esto es, $18.6 \%$ del total. Esto probablemente es un reflejo del lazo inicial que unía a este pueblo con Cisteil, porque este último fue fundado originalmente por individuos de una parcialidad de Tixcacaltuyú. Seguían en importancia los de Tahdziu (ubicados al sur de Cisteil) y Tiholop

44 Autos Criminales, fols. 251-252, 304-305. (situado al este, cerca de Cisteil), pues se dijo que los habitantes de ambos pueblos los habían desertado en masa para unirse al movimiento en 1761. Estos dos pueblos contribuyeron con 10.5 y $8.9 \%$ del total (27 y 23 individuos) respectivamente. Si agrupamos con los tres pueblos anteriores a los de Tahdzibichén y de Tixméuac, pueblos que colindan con Cisteil al noreste y al oeste, entonces los documentos revelan que Cisteil y los pueblos de sus alrededores aportaron el 45\% del total.

Por lo tanto, es significativo señalar el gran número de individuos que vinieron de otros lados a Cisteil, ya sea para convertirse en miembros de un nuevo asentamiento o para unirse a la sublevación de 1761 . Esto salta a la vista cuando analizamos a los sentenciados de acuerdo con sus distritos de origen. Los Beneficios Bajos — que incluía tanto al propio Cisteil como a Tixcacaltuyú, Tahdzibichén, Tzanlahcat, Yaxcabá, Homún y Xocchel— fue la jurisdicción de origen de solamente el 27.9\% de los sentenciados, en tanto que Los Beneficios Altos — que incluía tanto Tahdziu y Tiholop como Tihosuco, Chikindzonot, Ichmul, Peto, Petulillo, Chacsinsinkín, Sacalaca y Tela- contribuyó con un porcentaje un poco mayor, $28.3 \%$. En tercer lugar estaba el partido de La Costa — con Tekantó, Mocochá, Temax y Bokobá entre los más importantes- de donde procedía el 16.3\%. La Sierra Alta y La Sierra Baja — donde destacan los pueblos de Maní y Mama- contribuyeron cada una con el 10.5\% del total. El barrio de San Cristóbal en la ciudad de Mérida era el lugar de origen de no menos de nueve personas, esto es el 3.5\%. Finalmente, cinco individuos - $1.9 \%$ — eran del partido de Valladolid y otros dos eran del Camino Real Bajo. Sólo una persona -Jacinto Uc de los Santos, el propio Canekera de Campeche.

Es importante señalar una vez más que estos números no se refieren exclusivamente a los individuos que dejaron sus pueblos para unirse a la rebelión. Muchos de ellos con seguridad los habían dejado antes de 1761 para convertirse en miembros de la nueva comunidad que se estaba formando en Cisteil. Por tanto, los registros nos revelan que el reclutamiento atrajo individuos de un área extendida, ya sea por colonización o por participación en el movimiento de 1761. Casi con seguridad podemos afirmar que aquellos registrados como provenientes de 


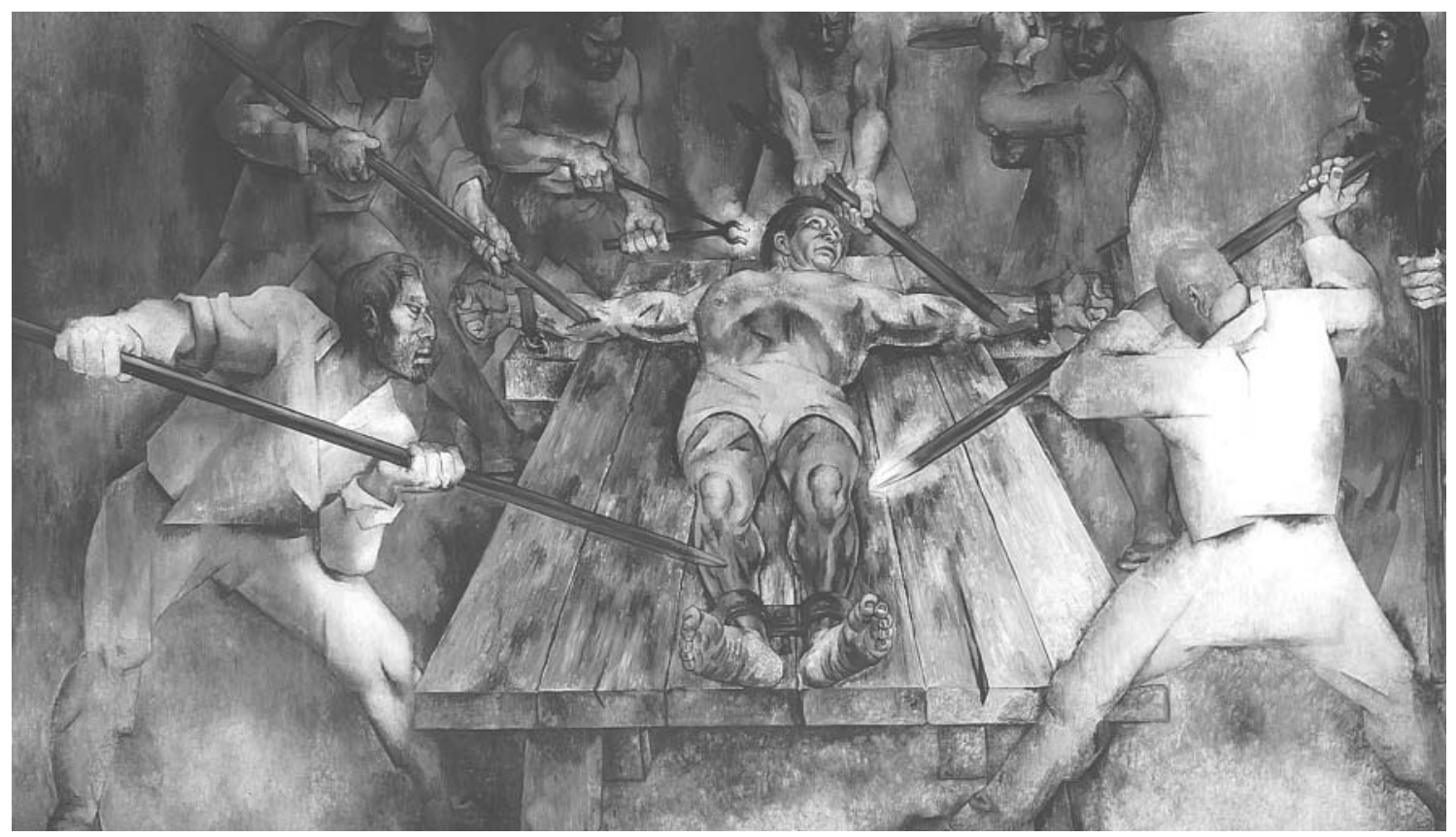

Fernando Castro Pacheco, De la vida colonial, el suplicio de Jacinto Canek.

los Beneficios Altos eran individuos que se unieron a la rebelión partiendo de asentamientos relativamente cercanos a Cisteil. Probablemente es el mismo caso de algunos provenientes del partido de La Sierra Alta que colinda con Cisteil hacia el oeste. Por otra parte, llama la atención que una proporción significativa de aquellos que recibieron sentencias eran de La Costa y de La Sierra Baja, y ambos partidos estaban experimentando la sobrepoblación a mediados del siglo XVIII como resultado del crecimiento demográfico. Como muy pocos individuos de la muestra eran de Valladolid o de Campeche, jurisdicciones con menos densidad de población, es probable que una proporción significativa de la población que migró de sus pueblos de origen para colonizar regiones con menor población —como los alrededores de Cisteil— vino de La Costa, La Sierra Baja y probablemente La Sierra Alta. En síntesis, la historia del recién fundado y "rebelde" Cisteil demuestra la significativa movilidad geográfica de los mayas coloniales de Yucatán. Nuevas tierras eran cultivadas por colonias de individuos de un pueblo de origen —en este caso Tixcacaltuyú — a quienes se les unían migrantes de regiones sobrepobladas de la provincia. Al mismo tiempo, los campesinos de un pueblo deben haber tenido un contacto considerable con personas de otros lugares con quienes intercambiaban información. En el juicio, por ejemplo, muchos testificaron que en Cisteil vieron personas que conocían de otros pueblos y haciendas. ${ }^{45}$ Debido a este contacto compartían elementos culturales comunes, incluyendo el conocimiento de Moctezuma y la promesa del rey que vendría del este para comenzar un nuevo ciclo en la historia. Como resultado, en un punto del tiempo los mayas intentaron recobrar su propio pasado con el objeto de tener un futuro autónomo. Sólo la fuerza de las armas les impidió hacerlo.

\section{CONCLUSIONES}

La rebelión de los mayas de Yucatán en 1761 puede ser entendida —al menos en parte- como un movimiento de revitalización, que ha sido definido como "el esfuerzo deliberado, organizado y consciente de los miembros de una sociedad para construir una cultura más satisfactoria" 46 La cultura existente no era satisfactoria para sus

\footnotetext{
45 Testimonio de Autos fhos. (1761), fols. 130, 153-157.

${ }^{46}$ Anthony F. C. Wallace, "Revitalization Movements: Some Theoretical Considerations for Their Comparative Study", American Anthropologist, vol. 58, núm. 2, 1956, p. 265.
} 
miembros debido al colonialismo, que había desplazado a los mayas de posiciones de control político y religioso; Jacinto Canek expresó el deseo de los mayas de controlar su sistema político al tener a uno de sus miembros sirviendo como rey y de controlar su estructura religiosa al investir a su rey de poderes sacerdotales para comunicarse con el mundo sobrenatural.

Más aún, en un hecho común en los movimientos revitalizadores, la forma de reconstrucción cultural elaborada durante la rebelión fue concebida por un solo individuo -Jacinto Uc de los Santos- cuya historia personal se desviaba de las normas culturales y se conformaba con la vida de un chamán: el hombre que se convirtió en Canek erró como pordiosero adivinador, comprometido con rituales secretos más allá de los límites aceptados por la sociedad colonial y llevó a cabo "una empresa profética y evangélica [...] socialmente inconveniente para la esposa [en consecuencia Uc no tenía], ${ }^{47}$ los parientes [ninguno fue mencionado], el empleador [tampoco tenía], carcelero [los oficiales coloniales que primero lo azotaron y luego lo ejecutaron] u otro tipo de asociación cercana con personas". ${ }^{48}$ Su visión de la nueva sociedad en turno fue "administrada en gran parte por el liderazgo político más que por el religioso", 49 porque Jacinto Uc de los Santos se convirtió en Canek cuando los caciques de los pueblos cercanos y el teniente de Cisteil lo reconocieron como tal y ordenaron a los indígenas que se sometieran al profeta carismático que aceptó "el liderazgo, auxilio y dominio de lo sobrenatural [...]; como Dios es al profeta, así (o casi) es el profeta a sus seguidores". ${ }^{50}$ Jacinto Uc de los Santos, ya como Canek, fue "tenido como una persona misteriosa, de autoridad incuestionable en una o más esferas del liderazgo, sancionado por lo sobrenatural [...] Así al líder carismático, no sólo se le permite sino que se espera que dirija su llamado a sus seguidores como una demanda para realizar un deber a un poder más alto que

\footnotetext{
47 Vale la pena notar que Jacinto Uc de los Santos era soltero al momento de la rebelión. Era extremadamente raro que un indígena adulto varón en ese momento no tuviera esposa.

48 Wallace, "Revitalization Movements", pp. 272-273.

49 Wallace, "Revitalization Movements", p. 273.

50 Wallace, "Revitalization Movements", pp. 273-274. Aquí Wallace emplea el concepto de líder carismático de Weber.
}

el humano."51 Su demanda de apoyo, desde luego, fue hecha en nombre del dios-emperador Moctezuma.

Finalmente, una vez que el movimiento llegó al poder, se dio la revitalización cultural. Los seguidores participaban en rituales cristianos, semi-cristianos y no cristianos. Creyeron que un mundo sobrenatural controlado por los mayas los protegería del peligro real representado en su forma material en las balas disparadas por las armas españolas. Canek supuestamente designó personas para ocupar los más altos cargos de las jerarquías civil y religiosa; de hecho, fueron los miembros de la élite política local ya existente porque no había nadie de un nivel mayor. En efecto, los mayas estaban recreando una estructura social completa al ocupar las más altas posiciones políticas y religiosas que se les habían negado después de la imposición del colonialismo. Y el líder carismático finalmente reclamó ser, o representar, uno de los divinos monarcas tradicionales de la historia nativa.

$\mathrm{Al}$ mismo tiempo, la rebelión fue un movimiento nativista. Intentó derribar al régimen colonial y muchos de los seguidores creyeron que el movimiento eliminaría también a los españoles. El mismo Canek, sin embargo, aparentemente dijo que las mujeres españolas serían preservadas con el propósito de casarlas con hombres mayas. A aquellos que se unieron a la sublevación se les pidió que mataran determinados animales — cochinos- de origen español. Muchos lo hicieron a pesar de los efectos negativos que debió acarrear para la economía campesina.

Sin embargo, el movimiento también seleccionó ciertos elementos de la cultura extranjera, impuesta como parte del colonialismo, para profundizarlos. Decidieron matar cochinos pero no hicieron lo mismo con otros animales de origen español como gallinas, caballos y ganado. Pero lo más importante es que aspectos del cristianismo fueron mantenidos, presumiblemente porque eran apreciados o eran necesarios. Los cultos a la Virgen y a los santos se usaron para reforzar y legitimar el movimiento. Supuestamente Canek se puso la corona de la Virgen en su propia cabeza; los mayas utilizaron para sus ceremonias los

\footnotetext{
51 Wallace, "Revitalization Movements", p. 274.
} 


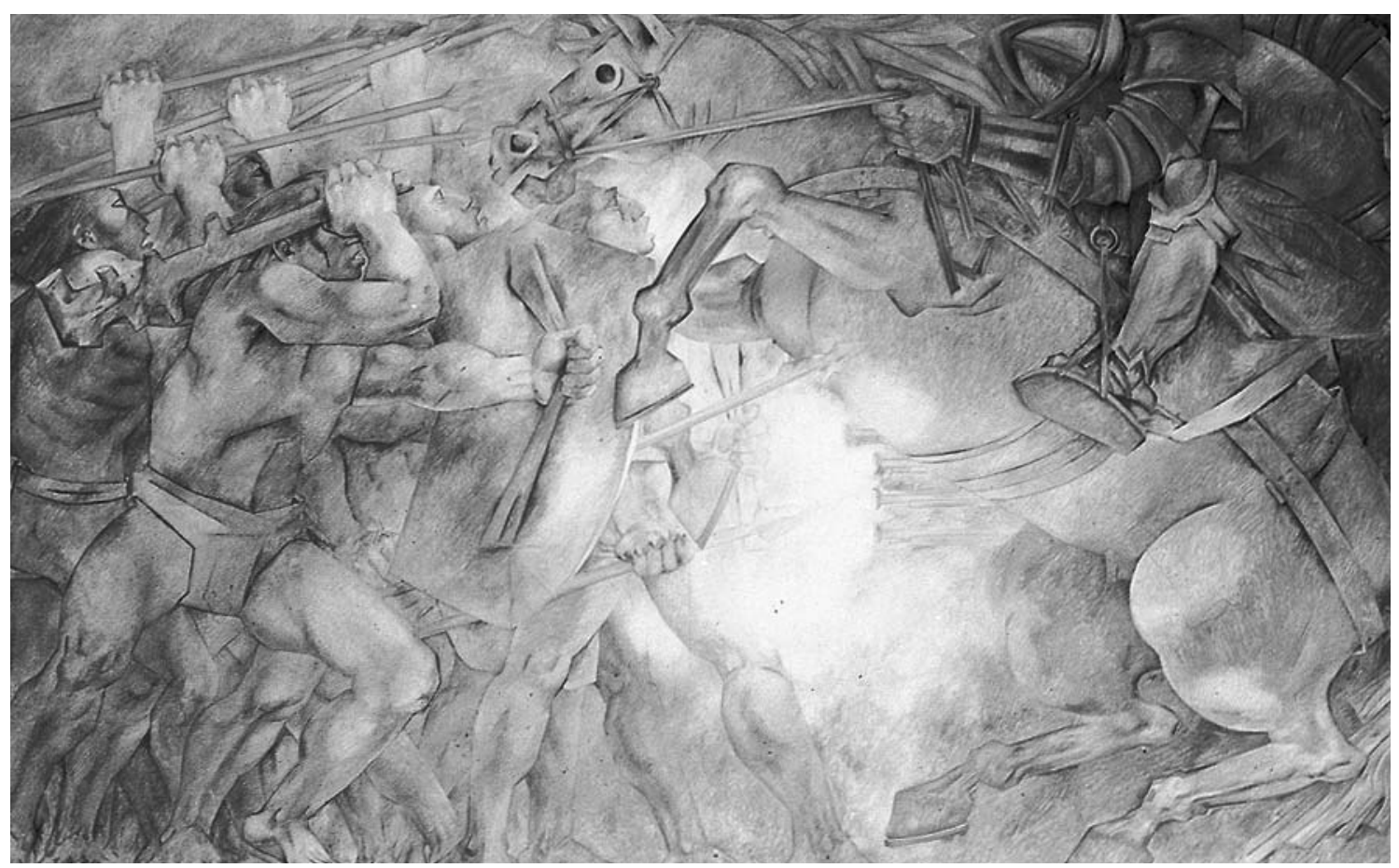

Fernando Castro Pacheco, La conquista.

edificios, las vestiduras de los sacerdotes católicos, el cáliz, los santos óleos, el rosario y los sacramentos del catolicismo. Canek proclamó la legitimidad de las bulas de indulgencia de la Santa Cruzada.

Estas características tienen un marcado contraste con las de otro importante movimiento de revitalización en Latinoamérica durante la Colonia, el conocido como Taki Onqoy, que amenazó al régimen colonial en el Perú en la década de $1560 .{ }^{52}$ Ahí los seguidores buscaron la total expulsión de todo lo español, incluyendo el cristianismo, y el restablecimiento concomitante de sus propias religiones. Pero Taki Onqoy existió dos siglos antes de la rebelión de Jacinto Canek. En Yucatán, para 1761, la aculturación había producido un sincretismo considerable, por lo que el exterminio de todas las cosas cristianas no era un

52 Véase Steve J. Stern, Peru's Indian Peoples and the Challenge of Spanish Conquest. Huamanga to 1640, Madison, 1982, pp. 51-71; Luis Millones, Rafael Varón Gabai, et al., El retorno de las huacas. Estudios y documentos sobre el Taki Onqoy, siglo XVI, Lima, 1990. asunto práctico ni deseable. Por lo tanto, los mayas decidieron mantener aquello que les gustaba - la jerarquía, el ritual elaborado, el culto de los santos y la teleología mesiánica- y desechar lo que les desagradaba, esto es, su posición inferior y subordinada —su marginación del poder - en la Iglesia. Esta situación es comparable con los eventos de 1712 en Chiapas donde los revolucionarios mayas conservaron una jerarquía eclesiástica y reclamaron el derecho a la autodeterminación religiosa al tiempo que trataron de impone pia soberanía. ${ }^{53}$ En síntesis, el cristianismo era una espada de dos filos: por un lado era usado por los españoles para pacificar a los indígenas, pero por el otro era usado por los indios para justificar la revolución violenta contra el colonialismo.

Desde este punto de vista, entonces, la rebelión de 1761 no fue simplemente un gran fracaso. Fue también el pre-

${ }^{53}$ Kevin Gosner, Soldiers of the Virgin. The Moral Economy of a Colonial Maya Rebellion, Tucson, 1992. 
sagio de lo que vendría. En el siglo XIX muchos mayas se unirían a otro gran levantamiento, la guerra de castas, que tuvo mucho más éxito que el movimiento iniciado por Jacinto Canek, y otra vez elegirían mantener elementos deseables del cristianismo: los rebeldes usaron una cruz (si bien una cruz parlante) en sus rituales y hasta negociaron con el gobierno estatal para que los sacerdotes fueran enviados a administrar los sacramentos. ${ }^{54} \mathrm{En}$ el siglo XX los mayas nuevamente procuran el control sobre su propia religión y tienen un éxito considerable en su intento. Porque al desertar del catolicismo en favor del cristianismo evangélico (que los católicos llaman "sectas"), los conversos, que ahora se cuentan por miles, han ganado lo que se les negó en el pasado: la autonomía religiosa. Esto no hubiera sido tolerado en la época colonial. Y podemos sospechar que así como los mayas tomaron lo que quisieron del catolicismo, lo mismo harán con esta nueva forma de cristianismo.

\section{Siglas y bibliografía}

AGI: Archivo General de Indias, Sevilla.

Bartolomé, Miguel A., 1978, La insurrección de Canek. Un movimiento mesiánico en el Yucatán colonial, México.

Bricker, Victoria Reifler, 1981, The Indian Christ, the Indian King: The Historical Substrate of Maya Myth and Ritual, Austin.

Clendinnen, Inga, 1987, Ambivalent Conquest. Maya and Spaniard in Yucatan. 1517-1570, Cambridge.

Cline, S. L., 1986, Colonial Culhuacan, 1580-1600. A Social History of an Aztec Tow, Albuquerque.

Farriss, Nancy M., 1978, "Nucleation versus Dispersal: The Dynamics of Population Movement in Colonial Yucatan", Hispanic American Historical Review, vol. 58, núm. 2.

— 1984, Maya Society Under Colonial Rule: The Collective Enterprise of Survival, Princeton.

Gosner, Kevin, 1992, Soldiers of the Virgin. The Moral Economy of a Colonial Maya Rebellion, Tucson.

${ }^{54}$ Para una famosa reseña de este tema, véase Nelson Reed, The Caste War of Yucatan, Stanford, 1964; también Terry Rugeley, Yucatán's Maya Peasantry \& the Origins of the Caste War, University of Texas Press, Austin, 1996.
Hill, Robert M., 1984, "Chinamit and Molab: Late Postclassic. Highland Maya Precursors Of Closed Corporate Community", Estudios de Cultura Maya, vol. XV.

— 1989 , "Social Organization by Decree in Colonial Highland Guatemala”, Ethnohistory, vol. 36, núm. 2.

Huerta, María Teresa y Patricia Palacios (eds.), 1976, Rebeliones indígenas de la época colonial, México.

Landa, Diego de, 1973, Relación de las cosas de Yucatán, Porrúa, México.

Miller, Arthur G., 1982, On the Edge of the Sea: Mural Painting at Tancah-Tulum, Quintana Roo, México, Washington, Dumbarton Oaks.

Millones, Luis, Rafael Varón Gabai et al., 1990, El retorno de las huacas. Estudios y documentos sobre el Taki Onqoy, siglo XVI, Lima.

O’Reilly, Justo Sierra, 1954, Los indios de Yucatán, 2 vols., Mérida.

Parmentier, Richard J., 1979, "The Mythological Triangle: Poseyemu, Montezuma and Jesus in the Pueblos", en William C. Sturtevant (ed. general), Handbook of North American Indians, vol. 9, Washington.

Patch, Robert W., 1979, A Colonial Regime: Maya and Spaniard in Yucatan, tesis doctoral, Princeton.

—, 1993, Maya and Spardian in Yucatan, 1648-1812, Stanford University Press.

_ 1991, "Decolonization, the Agrarian Problem, and the Origins of the Caste War in Yucatan, 1812-1847", en Jeffery T. Brannon y Gilbert M. Joseph (eds.), Land, Labor and Capital Modern Yucatan: Essays in Regional History and Political Economy, University of Alabama.

Quezada, Sergio, 1990, Pueblos y caciques yucatecos, 15501580, tesis doctoral, El Colegio de México.

Reed, Nelson, 1964, The Caste War of Yucatan, Stanford.

Rugeley, Terry, 1996, Yucatan's Maya Peasantry \& the Origins of the Caste War, University of Texas Press, Austin.

Spicer, Edward H., 1962, Cycles of Conquest, the Impact of Spain, Mexico and the United States on the Indians of the Southwest, 1533-1960, Tucson.

Stern, Steve J., 1982, Peru's Indian People and Challenge of Spanish Conquest, Huamanga to 1640, Madison.

Villa Rojas, Alfonso, 1961, "Notas sobre la tenencia de la tierra entre los mayas de la antigüedad", Estudios de Cultura Maya, vol. I.

Wallace, Anthony F. C., 1956, "Revitalization Movements: Some Theoretical Considerations for their Comparative Study", American Anthropologist, vol. 58, núm. 2.

Young, Eric Van, 1993, "The Cuautla Lazarus: Double Subjectives in Reading Texts on Popular Collective Action", Colonial Latin American Review, vol. 2, núms. 1-2. 